\title{
Editorial
}

\section{Back to the future: The role of cytochrome $c$ in cell death}

\author{
Boris Zhivotovsky ${ }^{1}$, Kaido P. Hanson ${ }^{2}$ and Sten Orrenius ${ }^{1,3}$ \\ ${ }^{1}$ Institute of Environmental Medicine, Karolinska Institutet, Box 210, S-171 77 \\ Stockholm, Sweden \\ 2 Laboratory of Molecular Oncology, N.N. Petrov Research Institute of Oncology, \\ 188646 St. Petersburg, Russia \\ ${ }^{3}$ corresponding author: tel +468335874 fax +468329041
}

Recent developments have placed the mitochondria in the focus of apoptosis research (Orrenius et al, 1997 and references therein). Increasing evidence supports the hypothesis that factors released from these organelles, notably cytochrome $c$, can serve to activate cytoplasmic caspases and thereby trigger the execution phase of apoptosis (Liu et al, 1996). Similarly, microinjection of cytochrome $c$ into various cell types has been found to cause cell death by apoptosis (Li et al, 1997a; Zhivotovsky et al, 1998). Whether cytochrome $c$ release from mitochondria is preceded by mitochondrial permeability transition and loss of the transmembrane potential is still a controversial issue (Kroemer, 1997; Yang et al, 1997; Kluck et al, 1997). It is also unknown if all caspases are equally sensitive to cytochrome $c$-mediated activation.

However, the observations that alterations in mitochondrial function and release of cytochrome $c$ may be of importance for cell death are not novel. Before the epoch of apoptosis, cell death was studied quite intensively in radiation biology, because it is the ultimate effect of ionizing radiation. Studies of radiation-induced alterations in the cellular bioenergetic machinery was one of the most actively developing areas in radiobiology in the 1950s and 1960s (Ashwell and Hickman, 1952; vanBekkum, 1957; Scaife, 1964; Manoilov, 1968). Cell death was divided into reproductive cell death (dependent on the mitotic cycle) and interphase cell death (Okada, 1970). The latter was early regarded as a classic example of apoptosis (Hanson, 1979; Yamada and Ohyama, 1988). More recently, it has become clear that radiation-induced reproductive cell death often also occurs by apoptosis. Furthermore, tissues were divided into radiosensitive (thymus, spleen, small intestine, etc.) and radioresistant (liver, heart, brain, etc.) according to the early appearance of cell death after irradiation (Bacq and Alexander, 1961).

During the search for mechanisms of early massive cell death in radiosensitive tissues in the 1950s, suppression of oxidative phosphorylation in mitochondria from thymus and spleen was described (Ashwell and Hickman, 1952). This phenomenon was not seen in the mitochondria from radioresistant tissues (Hanson and Mytareva, 1967). The suppression of oxidative phosphorylation was observed 30-60 min after whole-body X-irradiation of rats with relatively low doses of radiation (50-100 cGy) (vanBekkum, 1957). In radiosensitive tissues, the suppression of oxidative phosphorylation was associated with the formation of pyknotic nuclei (vanBekkum et al, 1964). Using selective dyes, it was found that there was a retardation of electron transport between cytochromes $b$ and $c$ in thymus mitochondria which exhibited lower levels of cytochrome $c$ after irradiation (Scaife, 1964). Thus, the radiation lesion was believed to be due to the looser binding of cytochrome $c$ to the mitochondrial inner membrane after X-irradiation.

This observation was in accordance with the previous finding that addition of exogenous cytochrome $c$ could stimulate oxidative phosphorylation in mitochondria isolated from radiosensitive, but not from radioresistant, tissues of irradiated rats (Manoilov and Hanson, 1964; Hanson and Mytareva, 1967). Loss of cytochrome $c$ was not a result of its simple escape from the mitochondria, since additional washing of the mitochondrial fraction with isotonic buffer did not increase the 'cytochrome $c$ ' effect (van Bekkum, 1957). Neither did in vitro irradiation of isolated mitochondria cause increased enzyme release (Scaife and Hill, 1963). Thus, it was suggested that the perturbation of mitochondrial electron transfer in radiosensitive tissues was based on a controlled release of cytochrome $c$ from the mitochondria and the appearance of the hemoprotein in the cytosol (Scaife, 1964, 1966). It is interesting to note that irradiation damage to cytochrome $c$ in vitro was appreciably less when it was in the fully reduced state rather than partially oxidized or undergoing alternative oxidationreduction changes. In strong support of these earlier observations are recent reports on cytochrome $c$ release from mitochondria in cells undergoing radiation-induced cell death (Kharbanda et al., 1997; Chauhan et al., 1998) and on the importance of the redox state of cytochrome $c$ during caspase activation in cytosolic extracts (Hampton et al., 1998).

It is also of interest that only a modest decrease in ATP levels was observed in thymus, spleen and ascites tumor cells following irradiation (Scaife, 1966). This observation suggested that the loss of functional cytochrome $c$ from the mitochondria was not large enough to markedly depress ATP production by the mitochondria or that this loss could be compensated for by glycolytic phosphorylation systems. In fact, several recent observations support the idea that a combination of cytochrome $c$ release and maintenance of a sizable intracellular ATP pool is required for the execution of the apoptotic suicide program (Tsujimoto, 1997; Nicotera and Leist, 1997). In recent reviews, Reed (1997) and Schendel (1998) discuss two pathways of cell killing by cytochrome $c$ released from the mitochondria. One of them involves activation of the caspase cascade by the 
interaction of the released hemoprotein with Apaf- 1 and pro-caspase- 9 in the cytosol, while the other one is related to the retardation of mitochondrial electron transport and subsequent impairment of ATP production and promotion of the generation of reactive oxygen species. This second pathway is very similar to the one described by Scaife (1966) many years ago.

Thus, the mitochondria and their release of cytochrome $c$ was in the focus of cell death research more than thirty years ago. The mechanism then was believed to be restricted to impairment of ATP production and enhanced generation of reactive oxygen species. The recent developments have added another mechanism, i.e. caspase activation by the released cytochrome $c$, which is now believed to be critical for the apoptotic process (Zou et al, 1997; Li et al, 1997). Future research will reveal whether there are additional mechanisms by which the mitochondria can kill their host cells.

\section{References}

Ashwell G and Hickman J (1952) Effects of X-irradiation upon the enzyme systems of the mouse spleen. Proc. Soc. Exptl. Biol. Med. 80: 407-413

Bacq ZM and Alexander P (1961) Fundamental radiobiology. Acad. Press, NY - L

Chauhan D, Pandey P, Agata A, Teoh G, Krett N, Halgren R, Rosen S, Kufe D, Kharbanda S and Anderson K (1998) Cytochrome c-dependent and independent induction of apoptosis in multiple myeloma cells. J. Biol. Chem. 272: 29995-29997

Hampton MB, Zhivotovsky BD, Slater AFG, Burgess DH and Orrenius S (1998) Importance of the redox state of cytochrome $c$ during caspase activation in cytosolic extracts. Biochem. J. 329: 95-99

Hanson KP (1979) Molecular mechanisms of interphase cell death. Radiobiology 19: 814-820 (In Russian)

Hanson KP and Mytareva LV (1967) Mechanisms of effects of ionizing radiation on oxidative phosphorylation in animals. Proc. Acad. Sci. (Estonia) 16: 80-87

Kharbanda S, Pandey P, Schofield L, Israels S, Roncinske R, Yoshida K, Bharti A, Yuan ZM, Saxena S, Weichselbaum R, Nalin C and Kufe D (1997) Role for Bcl-xL as an inhibitor of cytosolic cytochrome $c$ accumulation in DNA damage-induced apoptosis. Proc. Natl. Acad. Sci. USA 94: 6939-6942

Kluck RM, Bossy-Wetzel E, Green DR and Newmeyer DD (1997) The release of cytochrome cfrom mitochondria: A primary site for $\mathrm{Bcl}-2$ regulation of apoptosis. Science 275: 1132-1136

Kroemer G (1997) Mitochondrial implication in apoptosis. Towards an endosymbiont hypothesis of apoptosis evolution. Cell Death Differ. 4: 443-456
Li P, Nijhawan D, Budihardjo I, Srinivasula SM, Ahmad M, Alnemri ES and Wang X (1997) Cytochrome $c$ and dATP-dependent formation of Apaf-1/Caspase-9 complex initiates an apoptotic protease cascade. Cell 91: 479-489

Li F, Srinivasan A, Wang Y, Armstrong RC, Tomaselli KJ and Fritz LC (1997a) Cellspecific induction of apoptosis by microinjection of cytochrome $c$. Bcl- $x_{\mathrm{L}}$ has activity independent of cytochrome crelease. J. Biol. Chem. 272: 30299-30305

Liu X, Kim NC, Yang J, Jemmerson R and Wang X (1996) Induction of apoptotic program in cell-free extracts: Requirement for dATP and cytochrome $c$. Cell 86: $147-157$

Manoilov SE (1968) Primary mechanisms of biological effects of ionizing radiation. Meditsina, Leningrad

Manoilov SE and Hanson KP (1964) Effect of exogenous cytochrome con oxidative phosphorylation in mitochondria from tissues isolated from irradiated animals. Vopr. Medic. Chem. 10: 410-416 (In Russian)

Nicotera P and Leist M (1997) Intracellular ATP, mitochondrial function and the decision between apoptosis and necrosis. Cell Death Differ. 4: 435-442

Okada S (1970) In: Radiation Biochemistry (Altman KI, Gerber GB and Okada S, (eds.) Vol. 1, Academic Press, New York.

Orrenius S, Burgess DH, Hampton MB and Zhivotovsky B (1997) Mitochondria as the focus of apoptosis research. Cell Death Differ. 4: 427-428

Reed J (1997) Cytochrome c: Can't live with it - Can't live without it. Cell 91:559-562

Scaife JF (1964) The nature of the radiation-induced lesion of the electron transport chain of thymus mitochondria. Canad. J. Biochem. 42: 431-434

Scaife JF (1966) The effect of lethal doses of X-irradiation on the enzymatic activity of mitochondrial cytochrome $c$. Canad. J. Biochem. 44: 433-439

Scaife JF and Hill B (1963) Uncoupling of oxidative phosphorylation by ionizing radiation. II The stability of mitochondrial lipids and cytochrome $c$. Canad. J. Biochem. 41: 1223-1227

Schendel S, Montal M and Reed JC (1998) Bcl-2 family proteins as ion-channels. Cell Death Differ. 5: (in press)

Tsujimoto Y (1997) Apoptosis and necrosis: Intracellular ATP as a determinant for cell death modes. Cell Death Differ. 4: 429-434

vanBekkum DW (1957) The effect of X-rays on phosphorylation in vivo. Biochim. Biophys. Acta 25: 487-493

vanBekkum DW, deVries MJ and Klowen HM (1964) Biochemical and morphological changes in lymphatic tissues following partial-body irradiation. Internat. J. Radiat. Biol. 8: 395-401

Yamada T and Ohyama H (1988) Radiation-induced interphase death of rat thymocytes is internally programmed (apoptosis) Int. J. Radiat. Biol. 53: 65-75

Yang J, Liu X, Bhalla K, Kim CN, Ibrado AM, Cai J, Peng T-I, Jones DP and Wang X (1997) Prevention of apoptosis by Bcl-2: Release of cytochrome $c$ from mitochondria blocked. Science. 275: 1129-1131

Zhivotovsky B, Orrenius S, Brustugun OT and Doskeland SO (1998) Injected cytochrome $c$ induces apoptosis. Nature 391: 449-450

Zou H, Henzel WJ, Liu X, Lutschg A and Wang X (1997) Apaf-1, a human protein homologous to $C$. Elegans CED-4, participates in cytochrome $c$-dependent activation of caspase-3. Cell 90: $405-413$ 